\title{
Claudio Belini
}

Doctor en Historia por la Universidad de Buenos Aires (2004). Es investigador del Consejo Nacional de Investigaciones Científicas y Tecnológicas con sede en el Programa de Historia Económica y Social Americana (Pehesa) del Instituto de Historia Argentina y Americana "Dr. Emilio Ravignani". Su campo de investigación es la historia industrial y de las políticas públicas de la primera mitad del siglo xx. Recientemente ha publicado "El grupo Bunge y la política económica del primer peronismo, 1943-1952", Latin American Research Review, vol. 1, núm. 1, 2006.

\section{Resumen}

Este artículo estudia el conflicto legal que, iniciado en 1937, culminó en 1953 con la nacionalización de uno de los conglomerados financieros e industriales más poderosos de Argentina: el grupo Bemberg. Se sostiene que ese resultado constituyó una respuesta simbólica del peronismo a los años treinta, un tiempo de frustración para el movimiento obrero y de debilidad estatal. Sobre la base de nuevas fuentes documen- tales, se analiza la administración estatal de las empresas y los proyectos del primer peronismo (1946-1955) tendentes al traslado de las mismas a manos de cooperativas obreras y sindicales. A propósito de ello, el trabajo explora las cambiantes relaciones entre el poder económico y político en la Argentina de la primera mitad del siglo $\mathrm{xx}$.

Palabras clave:

Grupos económicos, industria, nacionalización, peronismo, sindicatos.

Fecha de recepción: Fecha de aceptación:

agosto de 2006 abril de 2007 


\title{
Monopolies, Power and Politics. Perón Against the Bemberg Group, 1948-1955
}

\author{
Claudio Belini
}

Ph.D. in History from the University of Buenos Aires (2004). Researcher at the National Council of Scientific and Technological Research in the Program of American Economic and Social History (PEHESA) at the Dr. Emilio Ravignani Institute of Argentinean and American History. His field of research is industrial history and public policies in the first half of the 20th century. He has recently published "El grupo Bunge y la política económica del primer peronismo, 1943-1952", Latin American Research Review, vol. 1, no. 1, 2006.

\begin{abstract}
This article studies the legal conflict that began in 1937 and culminated in 1953 with the nationalization of one of the most powerful financial and industrial conglomerates in Argentina: the Bemberg group. It holds that the result constituted a symbolic response by Peronism to the 1930 s, a time of frustration for the workers' movement and of state weakness. Using

the state administration of firms and the projects undertaken during the first phase of Peronism (1946-1955) which tended to transfer the former to worker and trade union cooperatives. A propos of this, the study explores the changing relations between economic and political power in Argentina during the first half of the 20th century.
\end{abstract} new documentary sources, the author analyzes

Key words:

Economic groups, industry, nationalization, Peronism, trade unions. 


\title{
Monopolios, poder y política. Perón contra el Grupo Bemberg, 1948-1959
}

\author{
Claudio Belini*
}

$G$ l estudio de las relaciones entre el régimen de Juan Domingo Perón y las grandes empresas es una de las dimensiones menos abordadas por la historiografía argentina. Si bien contamos con varios trabajos sobre el papel de las organizaciones empresarias nacionales durante el peronismo, no disponemos de análisis que intenten desentrañar la compleja vinculación entre el Estado y las grandes empresas. Ello es más sorprendente si se tiene en cuenta que en Argentina, como en el resto de los países de industrialización tardía, las grandes empresas y los conglomerados desempeñaron un papel preponderante en su transformación económica. ${ }^{1}$

*Agradezco los comentarios de Silvia Badoza, Marcelo Rougier, Hilda Sabato y Jorge Schvarzer y los árbitros anónimos de Secuencia. También deseo agradecer a Elizabeth Cipolleta del Archivo General de la Nación.

${ }^{1}$ En la historiografía argentina no existe consenso sobre si el predominio de los grandes grupos económicos resultó una fuerza impulsom o un freno al desarrollo en el largo plazo. La literatura es amplia e imposible de citar aquí. Para una visión optimista sobre el papel de los grandes grupos, véase Lewis, Crisis, 1993, y Rocchi, "Building", 1997. La perspectiva que pone énfasis en las trabas impuestas al desarrollo es sostenida por Schvarzer, Industria, 1996. Véase también Pineda, "Source", 2006.
El objetivo de este artículo es contribuir al análisis de esa temática mediante el estudio de un caso particular como fue la nacionalización del grupo Bemberg, uno de los conglomerados más importantes de Argentina. En la historiografía sobre el peronismo, el affaire Bemberg ha sido presentado como expresión del poder concentrado por Perón o bien como una venganza personal de su esposa Evita. ${ }^{2}$ En realidad, el caso Bemberg se inició en 1937 cuando una denuncia ante los tribunales de justicia condujo al gobierno nacional a iniciar un reclamo por la evasión del impuesto a la transferencia gratuita de bienes mediante la constitución de sociedades anónimas con residencia en el extranjero (tal vez una de las formas más utilizadas por los boldings existentes en Argentina). La posterior paralización del trámite ordinario lejos de disminuir el interés de la opinión pública sobre el tema lo exacerbó hasta convertirlo en uno de los escándalos económicos más importantes de los años treinta.

A partir de 1946, el nacionalismo económico alcanzó nueva fuerza cuando el gobierno peronista nacionalizó el Banco Central, los ferrocarriles ingleses y franceses, la compañía de teléfonos estaduniden-

\footnotetext{
${ }^{2}$ Lewis, Crisis, 1993, pp. 205-207.
} 
se y el comercio exterior. Pero la ofensiva estatal se mantuvo en esos límites. Si bien el régimen de Perón ensayó diversos instrumentos de contralor comercial y financiero de las grandes empresas, eludió la expropiación y la nacionalización de grandes sectores de la industria como la del cemento, los frigoríficos y las compañías de electricidad. El interés de Perón por impulsar una mayor industrialización se expresó a través de la aplicación de un conjunto variado de instrumentos de política industrial, entre los que sobresalía el control de las importaciones y el crédito de la banca oficial, que a menudo beneficiaron a las grandes empresas. ${ }^{3}$ En este sentido, este trabajo sostiene que la ofensiva de Perón contra el grupo Bemberg fue excepcional, en gran medida porque este se había convertido en un símbolo de la influencia política del poder económico y financiero antes del advenimiento de la "Nueva Argentina". Luego de la sanción de la ley 14.122 de 1952, que dispuso la liquidación del grupo Bemberg, el Estado adquirió las empresas a precio vil. La propiedad pública de las mismas planteó un conjunto de problemas económicos, organizacionales y legales, que requirieron la atención oficial. En forma paralela, esa nacionalización permitió al peronismo poner en marcha algunos de los objetivos más ambiciosos que se le conocen en el aspecto referido a la participación obrera.

La primera parte del artículo presenta brevemente cómo fue visualizada por el gobierno y la opinión pública la presencia de monopolios, y en especial la expansión del grupo Bemberg, en el periodo de en-

${ }^{3}$ Sobre la política crediticia véase Rougier, Politica, 2001, y Girbal, Mitos, 2003. Sobre la política industrial, consúltese Belini, "Industria", 2004. treguerras. La segunda analiza el conflicto legal que condujo al retiro del estatus legal a las empresas que conformaban el bolding. La tercera estudia el manejo peronista de las empresas cerveceras, textiles y agrícolas ganaderas. Nos interrogamos sobre las capacidades estatales para la creación y administración de empresas. Por último, la cuarta parte examina el periodo posperonista y relata los pasos que culminaron con la devolución de las empresas a sus anteriores dueños en 1959.

\section{MONOPOLIOS, PODER Y POLÍTICA ANTES DE PERÓN}

La modernización de la economía argentina como consecuencia de su exitosa integración al mercado internacional iniciada hacia 1870 dio lugar, en las primeras décadas del siglo $\mathrm{XX}$, al surgimiento de nuevas formas de organización económica que pusieron en primer plano la creciente concentración y centralización del capital. Este proceso, que afectó de manera similar al conjunto de las economías capitalistas y que encontraba su raíz en las grandes ventajas económicas, financieras y fiscales que las distintas formas de unión de empresas presentaban, reveló el surgimiento de nuevos problemas jurídicos y económicos.

En Argentina, estos problemas se presentaron por primera vez durante la Gran Guerra, cuando un importante crecimiento de la demanda de carne congelada atizó los conflictos entre los consumidores, los ganaderos y los frigoríficos estadunidenses, que ya controlaban el comercio exportador de carnes. En 1917, una comisión parlamentaria integrada por conservadores, radicales y socialistas inició una investigación sobre un conjunto de productos básicos 
como carne, azúcar, harinas, papas, vino, cal y petróleo, pero hubo que esperar hasta 1923 para que, en medio de una aguda crisis ganadera, el parlamento aprobara la ley 11.210 antitrust. $^{4}$

Por entonces, la concentración económica y, eventualmente, el desenvolvimiento de prácticas monopólicas, estaban afectando a vastos sectores de la industria. Entre ellos, la cervecera ocupaba un lugar de importancia debido a que se trataba de un producto de consumo popular, cuya demanda crecía vertiginosamente desde finales del siglo XIX. Fue precisamente durante la entreguerra cuando se afianzó el control de esa industria por parte del grupo Bemberg, un bolding que había nacido como una casa comercial a mediados del siglo XIX. ${ }^{5}$ En 1888, Otto Sebastián Bemberg había incursionado por primera vez en la industria cuando decidió establecer, con el apoyo económico de su padre y fundador de la dinastía, Otto Peter Bemberg, y de Ricardo Wendelstadt, la Brasserie Argentine Quilmes. En 1892 existían en el país 142 cervecerías, pero Quilmes elaboraba un tercio de la producción total del país, que superaba los 12000000 de litros. ${ }^{6}$ Durante las siguientes décadas, el fuerte crecimiento del consumo nacional, la concentración de la demanda en los distritos urbanos y los altos costos del transporte refrigerado de cerveza condujeron a sus propietarios a una estrategia consistente en la progresiva integración horizontal.

\footnotetext{
${ }^{4}$ Diario de Sesiones de la Cámara de Diputados de la Nación (en adelante DSCDN), 1920, vol. 5, pp. 999 1127. Para los pormenores de este episodio véase Smith, Carne, 1968.

5 Sobre los orígenes del grupo véase Marichal, "Gran", 1998, y Regalsky, Mercados, 2002.

${ }^{6}$ Rocchi, "Building", 1997, p. 38.
}

Este camino era alentado también por la disponibilidad de una tecnología de producción con bajos costos relativos, que permita el surgimiento de pequeñas empresas orientadas a satisfacer la demanda de los mercados regionales.

El poder económico del grupo Bemberg, construido sobre la base de su papel como agente financiero del Estado nacional y de las provincias, brindó los recursos necesarios para la estrategia de concentración horizontal. Una guerra de precios permitió a la Quilmes adquirir en 1907 la Cervecería Schlau, fundada en 1872. A comienzos de la década de 1910, Quilmes logró el control de Cervecería Palermo, empresa nacida en 1897 donde tenía intereses el grupo Tornquist. Entonces, las sociedades del grupo (Quilmes, Palermo y Schlau) formaron junto a las cervecerías Buenos Aires y Germania el Consorcio Cervecero Unión, que en 1913 fundaría la Cervecería del Norte en Tucumán. A la vez, Quilmes adquirió (y desmanteló) a Germania en 1915 y, cuatro años más tarde, a la Buenos Aires inaugurada en 1898.

La primera guerra mundial devino en la intervención francesa sobre las acciones controladas por Wendelstadt y su posterior liquidación a favor de Otto Sebastián. La guerra también tuvo otros efectos. La reducción del comercio internacional y la escasez de malta y de lúpulo de importación -insumos básicos para la elaboración de cerveza- se tradujo en una caída de la producción. Con el objeto de eliminar la dependencia creada por esta situación, en la siguiente década Bemberg fundaría la Cervecería y Maltería Los Andes y la Primera Maltería Argentina. En forma paralela, el grupo continuó con su estrategia de concentración horizontal; en 1921, adquirió la Cervecería San Martín de Bahía 
Blanca, empresa que sería clausurada un lustro más tarde. Renovadas guerras de precios le permitirían controlar la Cervecería Santa Fe y Bilz, una fábrica de gaseosas fundada en 1905. El control sobre el sector se afianzaría con la compra de las cervecerías Córdoba (1931) y Bella Vista (1939). ${ }^{7}$ En 1931, una revista calculó que el grupo controlaba cerca de $80 \%$ del mercado de cervezas, lo que le había permitido incrementar los precios y los beneficios. Para la revista debía revisarse esta estrategia, manteniendo el carácter popular del producto, "mejorando su calidad y su precio, con la certeza de que, a pesar de ello, el negocio rendirá siempre sus buenas utilidades, claro está, mientras no se pretenda la usura del 300 por ciento". ${ }^{8}$

A finales de la década de 1930, el control oligopólico de diversas ramas de la industria era un hecho documentado y seguía siendo motivo de discusión política. En la industria cervecera sólo tres plantas empleaban $54 \%$ del personal y producían $74 \%$ del valor agregado. ${ }^{9}$ El descubrimiento de nuevas maniobras tendentes a la evasión del contralor estatal por parte de frigoríficos y de las empresas eléctricas, y el auge del nacionalismo económico crearon una seria sospecha sobre la influencia política de los grandes grupos económicos. Pese a estos episodios, la legislación se mostraba impotente a la hora de combatir las prácticas monopólicas. Las fallas de la

${ }^{7}$ La Industria Cervecera, diciembre de 1931, p. 3, y noviembre de 1934, pp. 13-15. Caso, 1950, pp. 261-263.

${ }^{8}$ La Industria Cenvecera, julio de 1931, pp. 5-6. A pesar de la reducción de las ventas, Quilmes mantuvo altas ganancias durante la crisis de 1929 y la década siguiente. Véase, López, "Integración", anexo XIII.

${ }^{9}$ Armour, Technological, 1943, pp. 88-90. ley 11.210 , que habían dado a lugar a interpretaciones divergentes de los magistrados, se expresó en el hecho de que, durante su vigencia entre 1923 y 1946 , de 16 juicios sólo uno recibiera condena; el caso más resonante se produjo en 1925 cuando el Centro de Patrones Panaderos de Buenos Aires fue condenado en primera instancia por decidir en asamblea la elevación del precio del pan. En cualquier caso, ninguna de las grandes empresas resultó afectada. ${ }^{10}$ Como veremos, el principal conflicto que involucraría a un grupo empresario surgiría como consecuencia de una denuncia por evasión del impuesto a la herencia.

\section{EL PROBLEMA DEL IMPUESTO \\ A LA HERENCIA Y EL CONFLICTO CON EL PERONISMO}

El conflicto que terminaría con la liquidación del grupo Bemberg se inició en febrero de 1937 cuando un ciudadano denunció ante la justicia civil a los herederos de Otto S. Bemberg y Josefina Elertondo por la ocultación de bienes y la evasión del impuesto a la transmisión gratuita de bienes establecido por la ley $11.287 / 23$. Si bien Otto Sebastián y su esposa habían fallecido a principios de esa década, sus cinco hijos (Luis Emilio, Federico, Eduardo, Jorge y María Luisa, fallecida en 1921) no habían iniciado la sucesión. Sólo después de que la denuncia fue efectuada y que se

${ }^{10}$ La única condena firme se produjo en 1935 cuando la Unión de Cigarreros Mayoristas fue acusada por la Compañía Nacional de Tabacos de presionar a los comerciantes minoristas para no vender sus productos. Sobre los antecedentes de la ley, véase DSCDN, 1946, vol. 5, pp. 449-531. 
iniciara una investigación de oficio, los derechohabientes se avinieron a dar comienzo a la sucesión. Sin embargo, el hecho de que los herederos denunciaran como único bien un saldo de cuenta bancaria de 658000 pesos, exacerbó las sospechas. En 1940 el Consejo Nacional de Educación, beneficiario del impuesto, decidió relanzar la causa. Para entonces, el episodio había tomado estado público y se sumaba a la serie de escándalos financieros que los nacionalistas denunciaban como rasgo saliente de los gobiernos conservadores. ${ }^{11}$

En realidad, el problema de la evasión impositiva estaba generando un amplio consenso entre las fuerzas políticas que se acentuaría una vez que las consecuencias de la segunda guerra mundial sobre las exportaciones revelaran la fragilidad del sistema impositivo. Así, en 1942, el presidente Ramón Castillo propuso una serie de reformas fiscales entre las cuales se encontraba la del impuesto a la transmisión gratuita de bienes. El proyecto disponía que el gravamen recayera sobre el acto mismo de la transmisión, anulando así la posibilidad de que en el periodo existente entre este y su exteriorización judicial se realizaran operaciones con acciones, valores y títulos a fin de disminuir el monto imponible. Como observaba el despacho de la Comisión de Hacienda, apoyado por diputados conservadores, radicales y socialistas, el objetivo era poner fin a la evasión que "entre nosotros alcanza proporciones extraordinarias y en algunos casos lindantes con el escándalo". ${ }^{2}$

${ }^{11}$ El principal crítico fue el abogado nacionalista José Luis Torres, quien calificó como "década infame" los años de dominio conservador previos al peronismo. Véase Torres, Perduellis, 1943.

${ }^{12}$ DSCDN, 1942, vol. 3, p. 851.
A pesar de ello, el proceso contra los Bemberg sólo se aceleró a partir del golpe militar de 1943. El nuevo gobierno apoyó al interventor del Consejo, José Ignacio Olmedo, en su intención de poner fin a la investigación. En forma paralela, en agosto de 1943 se dictó el decreto 6755 mediante el cual aclaraba la ley de 1923 incorporando a los bienes gravados, las acciones de sociedades con propiedades locales que fueran transferidas fuera del país. Poco después, los representantes de los Bemberg depositaron 9000000 de pesos por concepto de pago del impuesto, sobre una sucesión que ahora se reconocía cercana a los $91000000 . .^{13}$ En agosto de 1944 , la comisión investigadora elevó un primer informe donde consideraba que el conjunto de las empresas era de propiedad de los Bemberg y que su organización como sociedades anónimas estaba destinada a ocultar bienes. ${ }^{14}$

En ese momento, el Consejo enfrentaba denuncias similares de autoridades provinciales para lograr el cobro de diversos impuestos, lo que derivaba en la posibilidad de dificultar la percepción del impuesto nacional. Por fin, en abril de 1947 , el Consejo presentó ante la justicia la liquidación del impuesto por 19451454 pesos, a los que se sumaban 33035053 pesos por concepto de intereses y una multa

${ }^{13}$ De todas formas, los Bemberg cuestionaron el decreto debido a que no era aclaratorio sino ampliatorio de la ley $11.287 / 23$, por lo que no podía ser aplicado con retroactividad.

${ }^{14}$ Temas Económicos e Industriales, agosto de 1944 , p. 30. La Comisión argumentó que los Bemberg eran propietarios de $51 \%$ de Quilmes, Palermo, Schlau, SAFAC y de la totalidad del capital de Estancias Santa Rosa. En cambio, los Bemberg afirmaron que sólo poseían $40 \%$ del capital de esas firmas. 
de 97257274 pesos. En total, los herederos debían abonar unos 140000000 de pesos, cifra superior en $18 \%$ al total imponible. $^{15}$

En forma paralela, la Inspección General de Justicia inició un estudio sobre las sociedades del grupo sobre la base de una nueva denuncia formulada por Torres. Esta investigación condujo un año más tarde, el 7 de abril de 1948, al retiro de la personería jurídica de las sociedades del grupo (que se describen en el cuadro 1 y la gráfica 1). Según se señalaba en el decreto 9997 , se había comprobado que las empresas eran entidades ficticias "creadas al solo fin de ocultar el patrimonio de los Bemberg, mediante una compleja trabazón de relaciones jurídicas simuladas, en continuo movimiento". ${ }^{16}$

Ante estas circunstancias, la familia Bemberg realizó un último intento por alcanzar un acuerdo con el régimen peronista. En una carta al presidente Perón, el nuevo conductor del grupo, Eduardo Bemberg, advirtió que:

La nueva generación que conmigo se hace cargo de la dirección de las empresas Bemberg tiene un concepto moderno de la función que corresponde al capital en la vida económica del país; deplora en consecuencia

${ }^{15} \mathrm{El}$ total imponible superaba los 114000000 y estaba compuesto por el valor de $51 \%$ del capital accionario de Brasserie, Schlau, Palermo y SAFAC, así como 632 acciones de Santa Rosa y el saldo declarado en CICA. El impuesto alcanzaba los 9700000 pesos pero era incrementado por un recargo del $100 \%$ por ausentismo, intereses anuales de $12 \%$ retroactivos a 1932, y una multa del quíntuplo del impuesto. Véase Musacchio, Impuesto, 1947, pp. 187-188.

${ }^{16}$ Anales de Legislación Argentina (en adelante, $A L A), 1948$, pp. 494-497. los errores cometidos y desea desarrollar sus actividades en armonía con los poderes públicos. ${ }^{17}$

Eduardo ofrecía el pago de todas las deudas impositivas, la aceptación de la multa de 90000000 y la liquidación de "aquellas sociedades que la familia Bemberg controla y que a juicio del poder ejecutivo convenga disolver, autorizándose la reestructuración de las que estén colocadas o se coloquen dentro de la ley". ${ }^{18}$ Atendiendo a esa estrategia, el 13 de junio de 1948 los herederos se allanaron al pago del impuesto y los intereses, dejando librado a la decisión judicial la procedencia de la imposición de la multa. ${ }^{19}$

Por fin, el 20 de diciembre de 1949, el juez Ismael Segovia condenó a los herederos a pagar una multa de 97000000 de pesos, fallo que fue confirmado, en octubre de 1950 por la Cámara de Apelaciones. Para entonces, la ofensiva gubernamental contra el bolding se había fortalecido dado que el Ministerio de Industria realizaba una amplia investigación bajo la sospecha de que había violado la nueva ley 12.906 de represión a los trusts. ${ }^{20}$ Estos acontecimientos y el fracaso de la tentativa empresaria de lograr un acuerdo con Perón con-

${ }^{17}$ Véase la carta reproducida en $D S C D N, 1952$, vol. 1, p. 331 .

${ }^{18} \mathrm{Ibid}$.

${ }^{19}$ Para garantizar el pago de la multa, los Bemberg depositaron acciones por un valor total de 97000000 de pesos. Archivo General de la Nación (en adelante AGN), Comisión Investigadora núm. 35, "Memoria", 1955, p. 15.

${ }^{20}$ La ley 12.906 de 1946 otorgó al ejecutivo facultad investigativa. Sólo en 1949 se instruyeron sumarios contra las firmas comercializadoras de algodón Anderson Clayton y Codeal, entre otras. 
Cuadro 1. Capital integrado en 1945 y año de fundación y nacionalización de las empresas Bemberg

\begin{tabular}{|c|c|c|c|c|}
\hline Fundación & Empresa & $\begin{array}{l}\text { Capital } \\
\text { integrado }^{\mathrm{a}}\end{array}$ & Actividad & $\begin{array}{l}\text { Compra } \\
\text { estatal }\end{array}$ \\
\hline 1889 & Brasserie Argentine Quilmes & $60000^{b}$ & Cervecería & L \\
\hline 1897 & Cervecería Palermo & 10000 & Cervecería & 1953 \\
\hline 1898 & Cervecería Buenos Aires & 3500 & Cervecería & 1953 \\
\hline \multirow[t]{2}{*}{1904} & Compañía de Tranways & & & \\
\hline & de Buenos Aires y Quilmes & 2500 & Transporte & 1954 \\
\hline 1905 & Bilz & 3900 & Bebidas sin alcohol & 1953 \\
\hline 1908 & Cervecería Schlau & 5000 & Cervecería & 1954 \\
\hline 1910 & Caja de Crédito Hipotecario & 3400 & Financiera & 1953 \\
\hline 1911 & Cervecería Santa Fe & & Cervecería & 1955 \\
\hline 1913 & Cía. Inmobiliaria El Sol & 2800 & Inmobiliaria & 1953 \\
\hline 1913 & Cervecería del Norte & 5000 & Cervecería & 1954 \\
\hline 1919 & Estancias Santa Rosa & 8000 & Industrial y ganadera & 1953 \\
\hline \multirow[t]{2}{*}{1919} & Crédito Industrial y Comercial & & & \\
\hline & Arg. & 60000 & Financiera & $\mathrm{L}$ \\
\hline 1920 & Primera Maltería Argentina & 16000 & Maltería & $\mathrm{L}$ \\
\hline 1921 & Maltería y Cervecería Los Andes & 5000 & Cervecería & 1954 \\
\hline 1922 & Cía. Argentina de Inmuebles & 20000 & Maltería & $\mathrm{L}$ \\
\hline 1922 & Cervecería Argentina Quilmes & 25000 & Maltería y cervecería & 1954 \\
\hline 1923 & Cervecería Córdoba & 4000 & Cervecería & 1955 \\
\hline 1924 & Manufactura Algodonera & 20000 & Textil & 1953 \\
\hline 1925 & $\begin{array}{l}\text { SEFAC. Sociedad Auxiliar, Fabril, } \\
\text { Agrícola y Comercial. }\end{array}$ & 10000 & Administración & 1953 \\
\hline 1925 & $\begin{array}{l}\text { Cía. Arg. Obras Sanitarias } \\
\text { de Quilmes }\end{array}$ & 2700 & Obras sanitarias & 1954 \\
\hline 1930 & Fruticultora Idahome & 3800 & Frutícola & 1954 \\
\hline 1931 & $\begin{array}{l}\text { Instalaciones y Aparatos para } \\
\text { el Despacho de Cerveza }\end{array}$ & 300 & Comercial & $\mathrm{L}$ \\
\hline 1933 & Fábrica de Levadura Martelli & 2500 & Levaduras & 1954 \\
\hline 1934 & Maltería y Cervecería Bella Vista & 1500 & Maltería & 1953 \\
\hline 1934 & Santa Margarita & 2500 & Agrícola ganadera & L \\
\hline 1934 & Invernadas San Sebastián & 8300 & Agrícola ganadera & 1953 \\
\hline 1935 & Fábrica de Levadura Fermolac & 750 & Levaduras & 1954 \\
\hline 1936 & Colonias y Estancias El Rodeo & 9500 & Ganadería & 1953 \\
\hline 1939 & Acevedo y Shaw & 1000 & Construcción & 1954 \\
\hline 1939 & Cía. Arg. Industrial Olivícola & 2000 & Aceitera & 1953 \\
\hline 1939 & $\begin{array}{l}\text { Cima. Cía. Industrial Mercantil } \\
\text { Americana }\end{array}$ & 2000 & Financiera & $\mathbf{L}$ \\
\hline
\end{tabular}




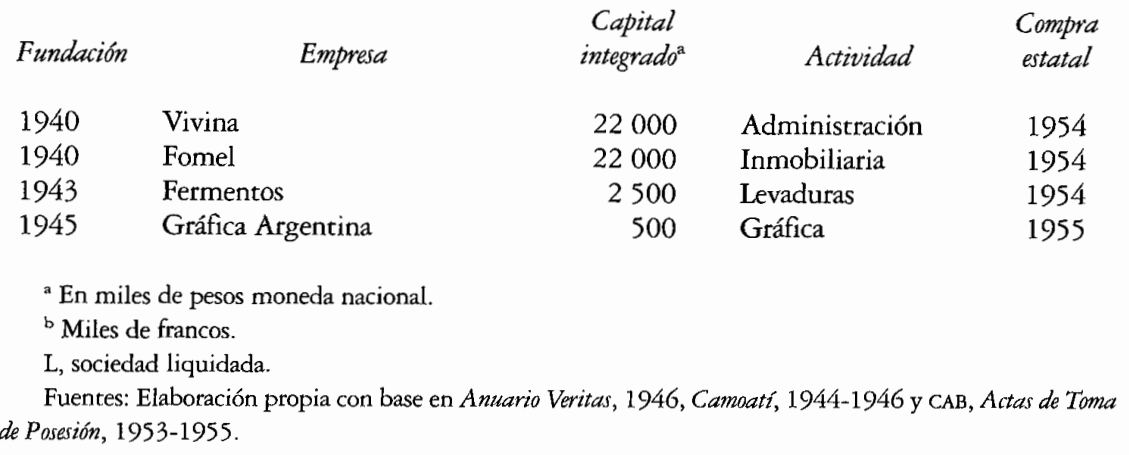

dujeron a la familia Bemberg a abandonar el país. Mientras tanto, desde abril de 1948 , las autoridades habían iniciado la liquidación de las empresas mediante el nombramiento de un interventor designado por el Ministerio de Justicia y bajo la dependencia del juez Segovia. El objetivo de esas ventas era hacer frente al pago de la deuda con el fisco de modo que algunos resultados fueron curiosos, como el hecho de que varias sociedades (Vivina, Fomel, Colonias y Estancias El Rodeo e Invernadas San Sebastián) fueron adjudicadas a miembros de la familia Bemberg, que ofrecieron comprarlas. En cambio, otras empresas fueron adquiridas por nuevos capitales. El caso más importante fue el de Manufactura Algodonera Argentina, una gran empresa textil. Por medio de un acuerdo, en octubre de 1950 el grupo Fabril Financiera adquirió 139546 acciones ordinarias por un valor de 13954600 pesos, lo que representaba $56 \%$ del capital de la firma. ${ }^{21}$ También fueron autorizadas las ventas de las cervecerías Santa Fe y 500.

${ }^{21}$ Vicepresidencia, Documentación, 1958, t. III, p.
Schlau, que fueron adquiridas por grupos empresarios de Santa Fe y de Rosario, respectivamente.

Las empresas más grandes del bolding, en cambio, lograron concertar un acuerdo con el fisco por medio del cual se disponía el nombramiento de nuevas comisiones liquidadoras y se respetaban los derechos de los accionistas franceses. Este fue el caso de la Brasserie Argentina Quilmes, que había absorbido el activo de las firmas CICA, Cía. Argentina de Inmuebles, Primera Maltería Argentina y en forma parcial de la Cía. Argentina Quilmes. Este convenio fue firmado por el ministro de Justicia y el embajador francés en julio de 1950, debido a que el gobierno galo se vio involucrado en la defensa de los accionistas franceses, entre los cuales se encontraban sobre todo miembros de la familia Bemberg; en los hechos se constituía una nueva sociedad denominada Enterprises Quilmes. Al mismo tiempo, se organizaba una nueva empresa denominada Cervecería y Maltería Argentina, y se designaban nuevas comisiones liquidadoras en las sociedades donde la Brasserie había tenido una importante participación accionaria. Para entonces, 


\section{SECUENCIA}

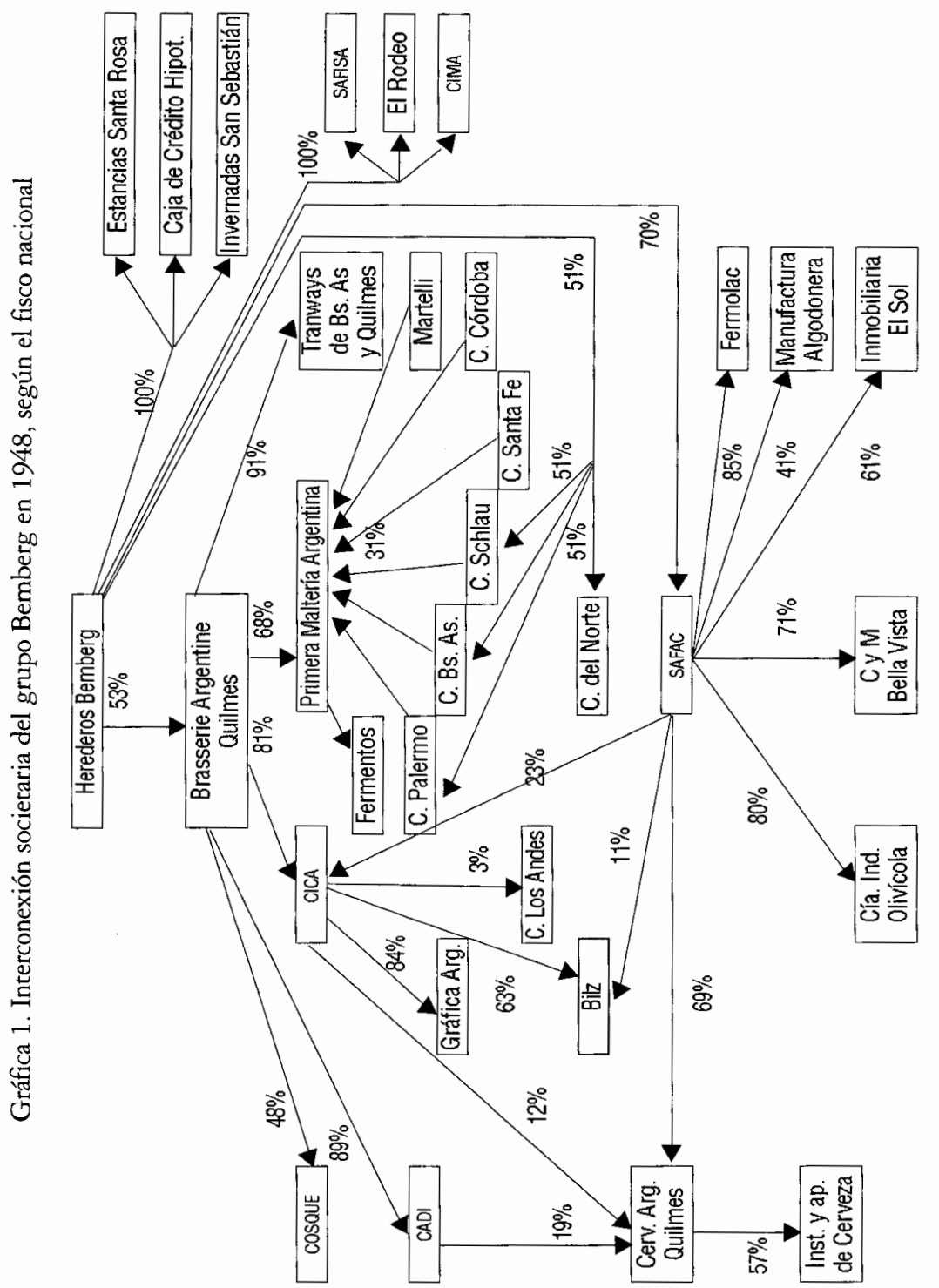

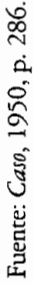


parecía claro que el gobierno de Perón propiciaba una rápida transferencia de las empresas a nuevos dueños. ${ }^{22}$

Sin embargo, la demora en la aplicación de las soluciones propuestas condujo a un cambio de estrategia a comienzos de 1952. Alegando que la liquidación de las sociedades se había tornado lenta, que varias de estas empresas volvían a manos de los Bemberg y que se estaba produciendo una fuga de capitales hacia Uruguay, ${ }^{23}$ Perón ordenó la sanción de una nueva ley que tendría como objetivo acelerar la liquidación. El proyecto establecía que las empresas serían vendidas bajo el procedimiento de liquidación sin quiebra. Con ese fin, se determinaba el nombramiento de nuevas comisiones liquidadoras compuestas por tres miembros designados por las sociedades en liquidación, Control del Estado (la agencia oficial de inteligencia) y otro liquidador de oficio, a las que el artículo 7 les otorgaba un periodo máximo de tres meses para finalizar su tarea.

En junio de 1952, el proyecto fue remitido al Parlamento. Contra lo que era la norma del accionar parlamentario, la ley fue aprobada por unanimidad en la Cámara Baja. Según el diputado radical Santiago Fassi, él mismo un denunciante del monopolio cervecero ante los tribunales de justicia en 1942, se había creado el clima de opinión necesario

a fin de que el proyecto no aparezca como un acto de confiscación o de persecución de capitales foráneos o argentinos, sino como una saludable reacción contra elementos

${ }^{22}$ AGN, Comisión Investigadora núm. 35, "Memoria", 1955, p. 19.

${ }^{23}$ Sobre la expansión del grupo en Uruguay, véase Bertino, "Integración", 2004, pp. 106-113. morbosos que han pretendido infiltrarse en nuestra economía.

En este sentido, el voto favorable del radicalismo ponía en evidencia que frente a esta cuestión no había posturas ambiguas:

Nadie podrá decir que este proyecto y la sanción subsiguiente no expresen el sentir de toda la Cámara de Diputados o que no esté en consonancia con el pensamiento de la opinión pública nacional sin distinción de matices. ${ }^{24}$

Este apoyo ilustraba hasta qué punto la elite económica, en la Argentina de la posguerra, era mirada con desconfianza y recelo por un amplio espectro de la sociedad argentina. ${ }^{25}$ La sanción de la ley ponía fin al proceso abierto en 1948 con el retiro de la personería jurídica. A la vez, marcaba el inicio de una etapa de enfrentamiento abierto entre Perón y los Bemberg, que conduciría pocos meses más tarde a la nacionalización de las empresas.

\section{LA NACIONALIZACIÓN DE LAS EMPRESAS Y LA ADMINISTRACIÓN DE LA CAB}

Luego de la sanción de la ley 14.122/52 la liquidación de las empresas tomó un ritmo acelerado. Ello fue el resultado de la decisión oficial de adquirir el conjunto de

${ }^{24}$ DSCDN, 1952, vol. 1, pp. 332 y 335.

${ }^{25}$ El acuerdo entre los partidos se quebró en julio de 1954 cuando un grupo de diputados peronistas presentó un proyecto destinado a expropiar los bienes inmuebles de la familia Bemberg, lo que fue rechazado por el radicalismo por constituir una persecución contra la familia. DSCDN, 1954, vol. 2, pp. 10321070 . 
las empresas y evitar su reabsorción por empresas privadas. Con ese fin, el gobierno decidió que la liquidación se realizaría a través de licitaciones y no por medio del remate público como establecía la ley de quiebras. Para controlar a los potenciales compradores se estableció que debían depositar el $20 \%$ del valor de las empresas en el momento de adjudicación y el $100 \%$ a la firma del boleto y que debían justificar el origen de su capital. ${ }^{26}$

Las primeras licitaciones tuvieron lugar en enero de 1953 e involucraron a nueve empresas. La adjudicación se produjo en abril y en todos los casos resultó favorecida la presentación oficial realizada a través de la Dirección Nacional de Industrias del Estado (DiNIE). ${ }^{27}$ En total, el Estado federal abonaría 228300000 pesos; 127800000 para adquirir cuatro cervecerías (Palermo, Bella Vista, Buenos Aires y Cervecería y Maltería Argentina), 24 para Estancias Santa Rosa, 50 para SEFAC, 20 para Manufactura Algodonera, 5500000 para la Caja de Crédito Hipotecario y 1000000 para la compra de la Cía. Industrial Olivícola. Contra lo establecido en las bases, el gobierno ofreció adquirir las empresas mediante la emisión de bonos públicos no negociables, con un interés anual del $3 \% .^{28}$ Poco después, sancionó un decreto mediante el cual gran parte del precio final de las empresas resultaba compensado por sus deudas impositivas.

A pesar de que la DINIE había sido adjudicataria de las empresas, el propósito

${ }^{26}$ AGN, Comisión Investigadora núm. 35, "Memoria", pp. 34-38 y pp. 47-59.

${ }^{27}$ Para una historia del organismo véase Belini "DINIE", 2001, pp. 97-119.

${ }^{28}$ Boletín de la Cámara de Comercio Argentino Alemana, núm. 24, 1953, p. 386. oficial de no incorporarlas definitivamente a la esfera estatal se expresó con la creación de una nueva empresa bajo la órbita del Ministerio de Hacienda. En efecto, el 23 de abril de 1953, el decreto 7365 creó la Comisión Administradora de Bienes (CAB), ley 14.122, que tendría como objetivo el gobierno de las empresas Bemberg. Su organismo ejecutivo sería un Consejo de Administración, presidido por el ministro de Hacienda e integrado por un vicepresidente y cuatro vocales nombrados por el poder ejecutivo. ${ }^{29}$

\section{El nacimiento de una nueva empresa estatal}

El mismo día de la constitución del ente, el Estado tomó posesión de las nueve empresas subastadas. La CAB decidió remover a los gerentes existentes y reemplazarlos por personal del Ministerio de Hacienda. También confeccionó "normas provisionales" para la administración de las empresas por medio de las cuales otorgó a las gerencias autonomía técnica, económica y financiera de acuerdo con los usos y costumbres de los negocios privados. Poco después, el vicepresidente Francisco Cholvis presentó un proyecto de organización de una gerencia y una secretaría generales que servirían como organismos de enlace en las relaciones entre la CAB y las empresas incorporadas. ${ }^{30}$

${ }^{29}$ AGN, Comisión Administradora de Bienes ley 14.122 ( $\mathrm{CAB}$ ), Actas del Consejo de Administración (en adelante, ACA), Sesión 1ra., 27 de abril de 1953, vol. 24 , p. 4.

${ }^{30} \mathrm{CAB}, \mathrm{ACA}$, Sesión 5, 27 de mayo de 1953, vol. 24 , p. 75 , y resolución 4 del 29 de mayo de 1953 , vol. 24 , p. 188. 
El 31 de diciembre de 1953, el poder ejecutivo aprobó el estatuto orgánico de la CAB. La norma estableció que esta funcionaría como una empresa del Estado, actuando como persona de derecho público en las relaciones jerárquico-administrativas y como persona de derecho privado en la esfera de las operaciones comerciales de las empresas. Por medio del artículo 2 se ratificó el criterio oficial según el cual las empresas debían cumplir una función económica social de acuerdo con el artículo 39 de la Constitución de 1949.

El estatuto legalizó la estructura de gobierno establecida hasta entonces, al ratificar a la CAB como órgano administrativo de las empresas. Entre sus atribuciones, la Comisión Administradora podía fijar el capital de las empresas; reestructurar, integrar, fusionar o descentralizar las mismas; adquirir o privatizar sus bienes inmuebles y muebles; realizar inversiones y contratar créditos con instituciones financieras oficiales o privadas; elevar el presupuesto de gastos. Además, el estatuto oficializaba la existencia de la gerencia general que, dependiente del presidente, constituía un ente ejecutivo de las órdenes dictadas por la CAB. A la vez, el gerente general debía "dirigir, supervisar y coordinar" el funcionamiento de las empresas; la presentación y cumplimiento de sus planes de producción, inversión y ventas; proponer el régimen de compras, de comercio exterior y de operaciones crediticias, y adoptar las medidas necesarias vinculadas con el desenvolvimiento de las mismas. ${ }^{31}$

El patrimonio de la CAB estaría integrado por el capital de las firmas incorporadas, las utilidades generadas por ellas y

\footnotetext{
${ }^{31}$ Decreto 26.157 en $A L A, 1953$, pp. 305-307.
}

los aportes que realizara el Estado. Una disposición especial establecía la forma en que se distribuirían las utilidades líquidas de las empresas: $20 \%$ sería integrado al Tesoro, $60 \%$ destinado a capitalización, y el $20 \%$ restante sería distribuido a través de gratificaciones entre su personal directivo, técnico y obrero.

En los años iniciales, la CAB debió hacer frente a la liquidación del grupo Bemberg, mediante la participación en las licitaciones judiciales donde invariablemente resultó adjudicataria de las empresas subastadas. Como se observa en el cuadro 1 , la CAB incorporó a su patrimonio la totalidad de las empresas, con excepción de la Cía. de Obras Sanitarias de Quilmes, que fue adquirida por ese municipio.

La incorporación de las empresas demandó a la $C A B$ el nombramiento de un importante número de gerentes y subgerentes. Allí surgió un conflicto de objetivos entre la posibilidad de mantener a los antiguos gerentes, de acuerdo con un criterio de estabilidad y buen gobierno de las firmas, o colocar nuevos, de mayor confianza de la $\mathrm{CAB}$ pero sin la experiencia y formación adecuada para estos cargos. Finalmente, los elencos gerenciales existentes en el momento de la nacionalización fueron desplazados. En su reemplazo, la CAB optó por la designación de personal del Ministerio de Hacienda. Por detrás de algunos desplazamientos, que en ocasiones incluyeron a personal técnico de las firmas, podía observarse la influencia que todavía conservaba la familia Bemberg. Así, por ejemplo, en octubre de 1953, la CAB removió a un directivo de Cervecería y Maltería Argentina

por su íntima vinculación con los anteriores patrones confesada por él mismo, que ha re- 
conocido haberse entrevistado con uno de los señores Bemberg fuera del país, situación que se traduce en actitudes obstruccionistas. $^{32}$

Para evitar esos inconvenientes, la administración de las empresas fue encargada a funcionarios públicos, con nula o escasa experiencia en la dirección empresarial. Aun así, la escasez de oferta de personal motivó que varios gerentes designados se desempeñaran al frente de más de una empresa, de modo que 16 de ellos se hicieron cargo de 26 empresas. En el extremo, se observa que sólo cuatro gerentes administraban doce empresas. Lo peor es que en todos los casos los gerentes designados lo hacían con retención de sus funciones públicas. En suma, el traspaso de ese conjunto empresarial a manos del Estado demandó una dotación de recursos gerenciales y técnicos para el cual no estaba preparado.

La nacionalización de las empresas también demandó el reemplazo de las formas de dirección que habían predominado en el pasado y, en especial, la administración centralizada del conjunto de empresas, jurídicamente autónomas, bajo la férula de la familia Bemberg y sus hombres de confianza. En sustitución de ello, el Estado intentó estructurar una organización gerencial moderna. Incluso, ordenó una reforma organizacional de un conjunto de empresas mediante la constitución de diferentes departamentos especializados en las fases comerciales, industriales, administrativas o inmobiliarias, decisión que representaba una innovación importante para el estado de la cultura empresaria local.

32 AGN, CAB, ACA, Sesión 25, 7 de octubre de 1953, vol. 26, p. 28.
Durante los primeros años de su gestión, la CAB tuvo un papel más activo en el gobierno de las empresas, aunque no por ello puede calificarse de eficiente. Entre 1.953 y 1955 realizaba reuniones semanales que incluían la presentación -por parte de los gerentes- de informes detallados sobre el desempeño de las firmas, sus necesidades financieras, sus planes de producción, venta y propaganda. $\mathrm{La} C A B$, a través de la gerencia general, intentó conducir una racionalización del conjunto de empresas a través de la fusión de unidades económicas de similar producción, la inversión para modernizar equipos y el incremento de la producción. Como veremos, estos objetivos tuvieron diferentes resultados que dependieron no sólo de la dotación de recursos humanos y económicos de cada firma, sino también de la decisión oficial de privatizar las empresas.

Con el fin de alentar la racionalización del conjunto industrial y mantenerlo como tal, era necesaria la liquidación de aquellos bienes muebles e inmuebles cuya subsistencia en la órbita estatal se consideraba inconveniente, por lo que la $\mathrm{CAB}$ decidió crear la empresa Comercial Inmobiliaria y Financiera Argentina (CIFA). Adicionalmente, la empresa administraría otras propiedades del grupo, activos financieros de distinta naturaleza (depósitos, créditos, acciones, títulos, bonos y obligaciones) en poder de las empresas pero ajenos a sus actividades. ${ }^{33}$ También atendería las nece-

${ }^{33}$ CIFA se creó mediante la fusión de la Cía. Inmobiliaria El Sol y la Caja de Crédito Hipotecario. AGN, CAB, ACA, Sesión 32, 25 de noviembre de 1953 , pp. 190-200. En mayo de 1954, CIFA recibió títulos y acciones pertenecientes a Empresas Quilmes S. A. En conjunto, CIFA tenía valores mobiliarios por 50000000 de pesos. 
sidades financieras del conjunto por medio de operaciones crediticias, así como actividades de importación y exportación, especialmente de malta. ${ }^{34}$

\section{El grupo cervecero: el camino a la cooperativa sindical}

La aplicación de la ley 14.122 y la decisión estatal de adquirir las empresas del ex grupo Bemberg, significó el control público sobre la industria cervecera. En efecto, en enero de 1953, el Estado adquirió cuatro de las firmas más importantes, a las que se sumarían a finales de 1.954 otras seis. Las primeras cuatro empresas (Cervecería y Maltería Argentina, Cervecería Palermo, Cervecería Buenos Aires y Maltería Bella Vista) representaban $88 \%$ del personal empleado en la industria (7 430 empleados, aproximadamente), en ese entonces integrada por 16 plantas. $\mathrm{Al}$ año siguiente, el Estado adquirió Cervecería del Norte, Maltería y Cervecería Los Andes, Maltería y Cervecería Cuyo, Cervecería Santa Fe, Enrique Meyer Cervecería Córdoba y Cervecería Schlau. Con excepción de esta última, las otras empresas habían finalizado el proceso inicial de liquidación previo a la sanción de la ley 14.122. Sin embargo, dado que se trataba de sociedades constituidas con arreglo a leyes provinciales, el gobierno de Perón presionó a sus gobernadores, quienes dieron marcha atrás en las medidas previas, colocando a las empresas

${ }^{34} \mathrm{El}$ objetịvo era desalentar el uso del crédito bancario y a la vez permitir que los excedentes obcenidos encontraran una canalización en inversiones. Inicialmente se autorizaron operaciones con plazo fijo de amortización, con un interés de $6 \%$, liquidable con la deuda principal. en manos de la justicia y, más tarde mediante licitaciones públicas, transfiriéndolas a la CAB. ${ }^{35}$

Junto a estas empresas, el Estado se hizo cargo además de un conjunto de firmas vinculadas a la producción cervecera. Entre ellas se contaban la Cía. de Tranvías de Quilmes, constituida para el transporte de cerveza y pasajeros hacia la ciudad de Buenos Aires; Bilz, una fábrica de bebidas gaseosas; y dos empresas dedicadas a la elaboración de levadura, que se habían fusionado en la Cía. Argentina de Levaduras (CALSA).

La administración de este conjunto industrial planteaba problemas comunes vinculados a las necesidades de materias primas, la dinámica sectorial, el estado de las maquinarias, las características del mercado de consumo interno y las políticas que desde el mismo Estado regulaban a la industria. La primera tarea de la CAB fue tomar conocimiento, a través de los informes presentados por los nuevos gerentes, de la situación de las empresas, el estado de las maquinarias y las perspectivas sectoriales. En relación con el primer punto, la principal empresa era la Cervecería y Maltería Argentina. ${ }^{36}$ Se trataba de un emporio industrial que incluía todas las fases de la

${ }^{35}$ Así, por ejemplo, la Cervecería Córdoba, que había sido privada de su personería jurídica en 1948, fue vendida tres años más tarde a una nueva sociedad compuesta por un grupo de industriales y comerciantes de la provincia conocido como grupo Meyer. Sin embargo, en septiembre de 1954, el gobierno de Córdoba retiró la personería a la nueva sociedad y dispuso su liquidación con arreglo a la ley 14.122. Véase AGN, Comisión Investigadora núm. 35, "Memoria", 1955, pp. 94-97.

${ }^{36} \mathrm{CAB}, \mathrm{ACA}$, Sesión 2, 13 de mayo de 1953, vol. 24, pp. $15-24$. 
producción cervecera y otras actividades industriales conexas. En 1952, la planta de Quilmes elaboró 1770000 hectolitros de cerveza (53\% del consumo nacional) dando ocupación a 750 trabajadores. A esa actividad se le sumaba la producción de gas carbónico, barras de hielo y diversos concentrados destinados a la producción de cerveza y bebidas sin alcohol. Adicionalmente, la empresa tenía una fábrica de levaduras con una capacidad de 3000 toneladas - que por medio de un acuerdo vendía a CALSA-, y una planta para la fabricación de tapas "corona", que utilizaba para su línea de cervezas pero que también vendía a otras empresas del grupo y demás fábricas privadas.

La distribución del producto se realizaba a través de una flota de 300 camiones y por medio del ferrocarril, que transportaba la producción desde la ciudad de Quilmes hasta Buenos Aires, donde contaba con cuatro depósitos con una capacidad de 200000 botellas. En el Gran Buenos Aires y en el Interior, la entrega la realizaba mediante 1200 concesionarios. A ellos se sumaban las sucursales establecidas en La Plata, Bahía Blanca, Rosario, Santa Fe, Paraná y Córdoba, donde se contaba con fábricas de hielo, soda y bebidas sin alcohol.

De conformidad con la estrategia del grupo destinada a fortalecer la posición de Quilmes, las otras empresas cerveceras tenían una importancia menor: Palermo seguía ocupando el mismo edificio desde su fundación y su capacidad de producción era de 300000 hectolitros, mientras que Cervecería Buenos Aires apenas alcanzaba los 90000 hectolitros anuales. La situación de la Maltería Bella Vista, que databa de mediados de la década de 1930 , era diferente, pues poseía una planta de fabricación de malta.
En cuanto al estado del capital invertido en las empresas, los informes pusieron en evidencia el escaso dinamismo tecnológico del sector. ${ }^{37}$ Así, por ejemplo, en Maltería Argentina el estado de las maquinarias era "precario"; en Palermo estaban en funcionamiento bienes de capital que databan de 1897, mientras la sección de botellería había sido instalada en 1919; en Cervecería Buenos Aires, el gerente informó que era urgente la renovación del cocedor, los tanques de agua caliente y la botellería, mientras que el gerente de CAISA señaló que la falta de inversiones y la utilización intensiva de los bienes de capital estaban colocando a la empresa en una situación difícil. ${ }^{38}$

Una excepción era Maltería Rosario, empresa que pertenecía a SAFAC. Se trataba de una nueva planta de producción de malta que el grupo Bemberg había decidido construir en vista de la aguda escasez de ese insumo en el mercado interno. Se preveía una capacidad de producción total de 50000 toneladas en seis secciones, pero para 1953 sólo se habían completado dos y la capacidad alcanzaba sólo 16000 toneladas. Con esta planta, se consideraban cubiertas las necesidades del mercado interno. 39

${ }^{37}$ Ya en 1947 las empresas presentaban un elevado grado de amortización del activo fijo en maquinarias: Cervecería Santa Fe (65\%), Maltería y Cervecería Los Andes (75\%), Cervecería del Norte (80\%), Cervecería Córdoba (64\%), Cervecería Buenos Aires (77\%). Camoatí, diciembre de 1947, pp. 20-30.

${ }^{38}$ Véase, respectivamente, AGN, CAB, ACA, Sesión 2, 13 de mayo de 1953, vol. 24, p. 15; Sesión 4, 20 de mayo de 1953, vol. 24, p. 52; Sesión 5, 27 de mayo de 1953, vol. 24, p. 93; Sesión 74, 15 de septiembre de 1954, vol. 29, pp. 214-219.

${ }^{39}$ AGN, CAB, ACA, Sesión 6, 3 de junio de 1953 , vol. 24, p. 135. 
A los problemas creados por la creciente obsolescencia del equipo productivo, se sumaban algunos cambios de coyuntura y de largo plazo que estaban afectando al mercado interno. A comienzos de la década de 1950, se alcanzó el mayor nivel de consumo de cerveza hasta entonces registrado en el país con 3900000 hectolitros. Pero a partir de 1952, la venta de cerveza comenzó a reducirse. Por un lado, la caída del poder adquisitivo de los salarios debilitó la demanda interna, como consecuencia de la acentuación de las presiones inflacionarias durante 1952. A largo plazo, el mercado se vio modificado por cambios en los patrones de consumo. En efecto, a partir de 1952 se inició un crecimiento sostenido de la compra de bebidas gaseosas que, alentada por novedosos sistemas de propaganda, terminó por deprimir la demanda de cerveza. En consecuencia, el consumo anual per cápita de cerveza descendió de 22 litros en 1951 a 6.5 litros en $1964 .{ }^{40}$

A comienzos de la década de 1950 , Bilz intentó responder a los cambios en los gustos del consumidor, ahora más favorable a las bebidas de cola. En 1953 se inició la producción de "Kola Bilz", un producto con el cual se pensaba competir en el mercado ya dominado por la filial de The Coca Cola Company. ${ }^{41}$ Pero la fir-

${ }^{40}$ OECEI, Argentina, 1966, pp. 188-189.

${ }^{41}$ Coca Cola, que se había instalado en 1941 , era la empresa líder del mercado contando con tres plantas donde trabajaban 780 obreros y empleados a mediados de la década de 1950. Le seguía Crush, subsidiaria de Orange Crush, que elaboraba los concentrados destinados a la preparación de "Naranja Crush" y "Bidú". La empresa de capital inglés Cervecería Bieckert, principal cervecería privada, embotellaba y distribuía esos productos. Cámara, Argentina, 1958, p. 59. ma no contaría con los recursos financieros necesarios para modernizar sus instalaciones ni lanzar una agresiva campaña publicitaria. En conjunto, los cambios en la coyuntura económica y la tendencia de mediano plazo a la reducción de la demanda de cerveza afectaron decisivamente el desempeño económico de las empresas.

Finalmente, a los problemas del mercado se sumaron los originados por las políticas peronistas de regulación de precios y salarios. Como en otras industrias, el gobierno respondió a las presiones inflacionarias implantando precios máximos. Sin embargo, al menos hasta 1952, el régimen se mostró incapaz para contener los incrementos salariales. El resultado previsible fue la reducción de las utilidades de las empresas. El caso más notable fue el de Bilz; así, en el ejercicio 1952, la combinación de precios máximos, el incremento del precio de las materias primas y la renovación de los convenios colectivos provocaron una pérdida de 550000 pesos, a pesar de que el monto de las ventas superaba los 23000000 de pesos. En parte, esta situación era el resultado de que sus 795 obreros y empleados estaban afiliados a la Federación Obrera Cervecera Argentina (FOCA) y no al sindicato respectivo (el de una fábrica de bebidas gaseosas), con lo que se beneficiaban del mayor poder de negociación y de los salarios más altos. ${ }^{42}$

La situación era menos dramática en las empresas cerveceras. A principios de 1954 tuvo lugar la denuncia de los convenios colectivos de 1952. Entonces, la $\mathrm{CAB}$

42 AGN, CAB, ACA, Sesión 27, 21 de octubre de 1953 , vol. 26, p. 105 . En los ejercicios 1953 y 1954 , los beneficios crecieron aunque su porcentaje con respecto al monto de las ventas se estancó en 3.5 por ciento. 
ordenó a los gerentes de las empresas concurrir a las negociaciones con la FOCA, teniendo como objetivo mantener los precios y condicionando todo aumento salarial a "un real incremento en la productividad". Según la CAB, los obreros cerveceros gozaban de salarios y de retribuciones sociales que estaban entre los más elevados de Argentina. Pero si eso había sido posible debido al auge del consumo y de la producción de los años de la posguerra, el cambio en las condiciones del mercado obligaba a una mayor cautela:

La situación de las empresas no es cómoda ni desahogada. Una celosa y austera política ha permitido hasta este momento la obtención de pequeños márgenes de ganancia, que comparados con los capitales invertidos, en el mejor de los casos no llegaron en el ejercicio próximo pasado a $3 \%$. Pero si se tiene en cuenta que esa ganancia de $3 \%$ ha sido calculada sin que haya podido reponerse una sola de las maquinarias actualmente en uso y que se encuentran en su mayor parte cumplidas en su vida útil, se verá cuánto importa ser ponderado en la consideración del problema planteado. ${ }^{43}$

Además, los incrementos de costos derivados de aumentos salariales en otras industrias que elaboraban materias primas y productos intermedios para la cervecera, hacían prever que "el quebranto económico será inevitable". ${ }^{44}$ Finalmente, los representantes empresarios cedieron. El 14 de junio se firmó un nuevo convenio que implicaba importantes aumentos salariales. Sólo la autorización oficial de elevar

43 AGN, CAB, ACA, Sesión 50, 12 de abril de 1954, vol. 28 , p. 56.

${ }^{44} \mathrm{Ibid}$. los precios de la cerveza de un litro en el orden del $11 \%$ y de la malta en $24 \%$, evitó el quebranto al costo de mantener deprimidos los márgenes de ganancia. ${ }^{45} \mathrm{El}$ episodio ponía en evidencia hasta qué punto, aun contando con la evidencia ofrecida por las empresas públicas, el gobierno era incapaz de contener las demandas obreras y condicionar todo aumento en las remuneraciones al incremento de la productividad.

Estos antecedentes explican, al menos en parte, por qué la política de administración de las empresas se modificó a mediados de 1954, cuando Perón expresó su intención de privatizarlas durante el doceavo congreso del sindicato cervecero:

El Estado no debe ni quiere ser competidor de la industria privada en renglones que, como los que integran el ex grupo Bemberg, no son específicos de su acción de gobierno. Quiere sí, dar a los auténticos productores, a los que con su esfuerzo de todos los días levantaron las fábricas y cimentaron las industrias, la real posibilidad de que lleguen a ser propietarios de esas fábricas y de esas industrias. ${ }^{46}$

La nueva orientación se inscribía en el intento oficial de limitar la intervención directa del Estado en el sector industrial,

${ }^{45}$ Las utilidades en relación con el capital por firma fue para Bilz, 21\%; Maltería Argentina, 2.7\%; Cervecería y Maltería Argentina, 3.2\%; Palermo, $10 \%$; y Buenos Aires, $-5.3 \%$. En conjunto, para las cinco firmas representó 3.6 por ciento.

${ }^{46}$ DSCDN, 1954, vol. 1, pp. 597 y 599. Fundada en 1936 , la FOCA se había volcado al peronismo en 1944. En esa etapa fue conducida por Alcides Montiel y Juan Carlos García, quienes fueron electos diputados. 
pero a la vez recogía la iniciativa peronista -presente ya en el proyecto de ley de accionariado del trabajo de 1946- de alentar la participación obrera en las empresas. La propiedad estatal de las empresas permitiría una tápida "privatización".

El proyecto no avanzó hasta comienzos de 1955. En el ínterin, la CAB resultó adjudicataria de nuevas empresas cerveceras. A la vez, encomendó y recibió un informe legal que afirmaba que el traspaso del grupo cervecero a la FOCA no crearía las condiciones para la violación de la ley contra los monopolios, que había sido uno de los argumentos oficiales para la sanción de la ley 14.122. La FOCA tenía personería jurídica y gremial; por lo tanto, una finalidad acorde al bien público y contraria a la búsqueda de ganancias extraordinarias provenientes del control del mercado. ${ }^{47}$

Por fin, el 1 de febrero de 1955, la $\mathrm{CAB}$ elevó el proyecto para la venta de las empresas al gremio cervecero. El contrato establecía que el gremio debía constituir una sociedad anónima denominada Fábricas Obreras Cerveceras Argentinas (FOCASA) que adquiriría trece empresas cerveceras y de actividades conexas. ${ }^{48}$ Las empresas eran compradas con sus pasivos y sus activos, marcas, patentes y licencias de explotación, por una suma total de 300000000 de pesos. Por medio del artículo 4 se establecía que se abonaría sólo el 10\% dentro

${ }^{47}$ AGN, CAB, ACA, Sesión 80, 27 de octubre de 1954, vol. 30, p. 154.

${ }^{48}$ Las empresas eran Cervecería y Maltería Argentina, Cervecería Palermo, Cervecería Buenos Aires, Cervecería del Norte, Nueva Cervecería Argentina, Cervecería Cuyo, Cervecería Schlau, Cervecería Córdoba, Cervecería Santa Fe, Bilz, las malterías Hudson y Bella Vista pertenecientes a Maltería Argentina, y CALSA, que agrupaba a las fábricas de levaduras. de los 90 días de concertado el acuerdo. El saldo sería cancelado por FOCASA mediante la emisión de obligaciones que, con una garantía especial de afectación de sus bienes inmuebles, serían adquiridas por el Estado. Las obligaciones, con un interés anual de sólo $4 \%$, debían ser amortizadas en 30 cuotas anuales. ${ }^{49}$

El capital social de FoCASA se fijó en 300000000 de pesos dividido en cinco series de 600000 acciones de 100 pesos cada una. El artículo 5 obligaba a la empresa a hacer suscribir las acciones, correspondiendo a la Confederación General del Trabajo (CGT) hasta 25\% del total y al gremio hasta $75 \%$. Pero a la vez, FOCASA se obligaba a prorratear entre los trabajadores hasta $50 \%$ de las acciones a medida que estos pudieran suscribirlas, ya sea por las utilidades que la empresa distribuiría entre los trabajadores o bien por el aporte voluntario de capital. ${ }^{50}$

El acuerdo también establecía que la CGT y la FOCA debían integrar las acciones con el $100 \%$ de las utilidades obtenidas. Adicionalmente, se establecía que la totalidad de las acciones serían nominativas, con el objeto de identificar a sus verdaderos propietarios.

49 "Proyecto de Compromiso de Compra Venta" en AGN, CAB, ACA, Sesión 95, 1 de febrero de 1955, vol. 31, pp. 206-211.

${ }^{50}$ La participación de cada trabajador no podría superar los 50000 pesos. En caso de retiro, jubilación o muerte del trabajador con anterioridad a la integración del valor de las acciones suscritas, este o sus herederos podrían optar por completar el valor de la acción o rescindirlas, reclamando el capital integrado a la par. Las acciones que retornaran a la FOCASA serían nuevamente redistribuidas entre sus obreros y empleados de acuerdo con disposiciones establecidas por el directorio de la empresa. 
En conjunto, el convenio establecía el accionariado del trabajo en las más importantes empresas cerveceras del país. Pero si bien se preveía el reparto de acciones entre los trabajadores, primaba el sistema de accionariado sindical con la propiedad del capital en manos de la central sindical nacional y del gremio cervecero. En efecto, en julio de 1955, la totalidad del capital fue suscrito por 21 dirigentes gremiales, que previamente habían firmado compromisos de transferencia de las acciones a la FOCA y la CGT. ${ }^{51}$

Otros detalles de la operación revelan que se trataba de un experimento inicial que, facilitado por el control estatal de estas firmas, recibía cuantiosos aportes financieros del gobierno a tal punto que el $10 \%$ inicial abonado por FOCASA provino de un préstamo oficial. Adicionalmente, investigaciones posteriores, que llevarían a la devolución de las empresas a manos estatales, determinaron que el precio de venta era extremadamente bajo: el patrimonio líquido del grupo cervecero ascendía a 605000000 de pesos, el doble del precio de venta oficial. De cualquier forma, la operación constituyó el más importante experimento en la materia encarado hasta entonces.

La experiencia del control gremial fue breve. En noviembre de 1955, pocas semanas después del derrocamiento de Perón, una comisión oficial se hizo cargo de la empresa. Tras elaborar un informe, la comisión solicitó al gobierno militar del general Pedro E. Aramburu la nulidad del acuerdo de febrero. Las diferencias entre el convenio original y el decreto de autorización de FOCASA, las concesiones financie-

${ }^{51}$ AGN, Comisión Investigadora núm. 35, "Informe Preliminar", 20 de noviembre de 1955, pp. II-IV. ras acordadas y el bajo precio de venta fueron denunciadas como flagrantes violaciones a varias disposiciones del Código Civil y de la ley de empresas públicas. Por fin, el 18 de julio de 1956, un decreto dejó sin efecto el acuerdo de febrero y dispuso la devolución de las empresas a la $\mathrm{CAB} .{ }^{52}$

\section{Conflictos legales y problemas sectoriales: Manufacturera Algodonera}

La empresa textil Manufactura Algodonera había sido fundada en 1924 sobre la base de la firma Fernando Perés y Cía. y los aportes financieros de los grupos Fabril Financiera y Bemberg. Este último logró controlar la mayoría del capital accionario a partir de la crisis textil de 1938 . A comienzos de la década de 1950, la empresa era la cuarta hilandería y tejeduría de algodón del país y la segunda productora de calzado de yute, dando ocupación a 2500 obreros y empleados. Sin embargo, descle 1948 la empresa afrontaba un periodo de dificultades económicas. Un año después del retiro de la personería jurídica, en junio de 1949, la planta principal de Buenos Aires sufrió un incendio que inutilizó una importante sección de la hilandería. A este factor se le sumaron las derivaciones de la liquidación que se prolongarían sin resolución durante la siguiente década. Aunque en octubre de 1950 el juez Segovia había homologado un acuerdo por medio del cual el grupo Fabril adquiría las acciones en poder de los Bemberg, el gobierno obligó a dar marcha atrás a esa operación mediante la sanción de la ley

52 Decreto ley $12.965 / 56$ en ALA, 1956, pp. 761-762. 
14.122. Una nueva comisión liquidadora, con mayoría estatal, dispuso la venta de la empresa según las condiciones elaboradas por Control del Estado. ${ }^{53}$ Por fin, en enero de 1953, bajo la protesta de los accionistas privados, la firma fue nacionalizada. ${ }^{54}$

Otros problemas que debía enfrentar la empresa estaban vinculados con el mercado textil, que mostraba una reducción importante de la demanda desde 1952. Durante la crisis, la empresa acumuló inventarios por 43000000 de pesos y, como consecuencia, su situación financiera empeoró notablemente. Para 1953, el capital disponible sólo representaba $53 \%$ de sus deudas con sus proveedores y con el Instituto de Previsión Social. En estas circunstancias, la nueva gerencia, instalada ese año, se propuso iniciar una racionalización productiva e incrementar el volumen de fabricación de acuerdo con la capacidad de la empresa. En primer término, planeó adquirir repuestos y maquinarias destinados a poner en funcionamiento algunas secciones paralizadas y renovar el stock de capital, que para 1952 había sido amortizado en $50 \%$. Adicionalmente, la gerencia propuso iniciar el trabajo en un tercer turno, pero estos planes debieron retrasarse como consecuencia tanto de la escasez de divisas como de la gran pesadez de las ventas. Como resultado de ello, la gerencia concentró sus esfuerzos en mejo-

${ }^{53}$ Es decir, el pago en efectivo del precio de compra. Dado que este se elevaba a 100000000 de pesos -aproximadamente 7000000 de dólares al tipo de cambio libre- era una operación inusitada en el mercado argentino.

${ }^{54}$ La propuesta privada en la licitación de 1953 fue presentada por Phila SA, una subsidiaria del grupo Fabril, por 75000000 de pesos pagaderos a plazos. DINIE la adquirió por 20000000 . rar las disponibilidades de la empresa a través de la realización de los inventarios. Para ello dispuso un plan de promoción de ventas por medio del cual se otorgaban premios a sus corredores y a los gerentes de las sucursales comerciales que la empresa tenía en las ciudades de Bahía Blanca, Córdoba, Mendoza, Resistencia, Rosario, Santiago del Estero y Tucumán. Por otro lado, la gerencia demandó al gobierno una modificación de la política de precios máximos que estaba reduciendo las utilidades. ${ }^{55}$

La instrumentación de esta estrategia durante 1954 permitió un incremento de la producción del orden del $15 \%$, pero una serie de factores seguían condicionando la situación de la firma. En efecto, la negativa del Banco Central de conceder permisos de cambio del orden de los 250000 dólares impidió la adquisición de repuestos y maquinarias. Por esta razón, la empresa no pudo reactivar la sección de hilado peinado que era la línea de producción que dejaba el mayor margen de utilidad. ${ }^{56}$ Por otro lado, si bien la firma incrementó sus ventas, el aumento sólo alcanzó 4.6\%. Además, este incremento escondía una caída en la venta de alpargatas de 24 por ciento.

La firma también debió enfrentar la renovación de los convenios colectivos en un momento en que el mercado textil mostraba una tímida reactivación. Luego de una larga negociación en que la Asociación Obrera Textil exigió incrementos superiores a los recomendados oficialmente,

${ }^{55}$ Otro problema era la gran rotación de los planteles obreros como consecuencia de que el sector textil abonaba salarios inferiores en relación con otras industrias. Sobre el tema Belini, "Industria", 2004, pp. 631-632.

${ }^{56}$ AGN, CAB, ACA, Sesión 125, 14 de mayo de 1955 , vol. 35 , pp. 137-138. 
el acuerdo fue firmado en mayo de 1954. Si bien entre 1953 y 1954 el personal empleado descendió de 2631 a 2456 (6.6\%), el importe total de remuneraciones y cargas sociales ascendió $20 \%$. La incidencia de las remuneraciones y cargas sociales sobre las ventas netas alcanzó $39 \%$, lo que representaba un crecimiento de cinco puntos en el término de un año.

Poco después de cerrado el ejercicio de 1954, en consonancia con la orientación privatizadora oficial, la $C A B$ ordenó a la gerencia general confeccionar un proyecto de venta por medio de una licitación pública. Se estableció que la propuesta ganadora debía abonar al menos $30 \%$ al contado y el saldo en diez cuotas anuales con $8 \%$ de interés. ${ }^{57}$ Para entonces, la CGT apoyaba una iniciativa de los trabajadores de la empresa a favor de la formación de una cooperativa obrera, designándose una comisión de obreros y empleados presidida por Alfredo Vivas (del Sindicato de Empleados Textiles de la Industria y Afines) y Andrés Framini (secretario general de la Asociación Obrera Textil).

A finales de junio de 1955 , la $\mathrm{CAB}$ abrió las propuestas de adquisición, pero la resolución definitiva no se tomó hasta octubre. Entonces, el gobierno militar que sucedió a Perón declaró desierta la licitación. En realidad, la venta de la empresa se veía dificultada por el embrollo legal que había resultado de la anulación del acuerdo de adquisición de Fabril Financiera y la posterior nacionalización, lo que había motivado sucesivas impugnaciones por parte de la Confederación General Empresaria y la Bolsa de Comercio porteña.

${ }^{57}$ AGN, CAB, ACA, Sesión 102, 30 de marzo de 1955, vol. 32, pp. 212-213.

\section{Las empresas agrícolas ganaderas}

Además de las importantes inversiones fabriles, los intereses del grupo Bemberg incluían también las actividades agrícolas ganaderas. En 1952 se había calculado que la fortuna en tierras del conglomerado alcanzaba las 235000 hectáreas. Con excepción de unas 11000 hectáreas ubicadas en Santiago del Estero y otras 25000 pertenecientes al establecimiento yerbatero Puerto Bemberg en Misiones, la mayor parte (alrededor de 199000 hectáreas) estaba ubicada en la región pampeana. ${ }^{58} \mathrm{La}$ más importante de estas empresas era Estancias Santa Rosa. Se trataba de una explotación que combinaba la cría y el engorde de novillos con la producción de cereales. La empresa se dedicaba a la industrialización de la leche y la producción de quesos de marcada reputación en el mercado interno.

Como era la norma en el grupo, Estancias Santa Rosa era propietaria de sólo una parte de las tierras dedicadas a la ganadería. El resto, $75 \%$ de las 82500 hectáreas en explotación, era arrendado a los miembros de la familia y otras empresas del grupo. ${ }^{59}$ Las existencias de ganado alcanzaban las 59200 cabezas, mayoritariamente de propiedad de la empresa, que se distribuían entre los 100 tamberos, a los que se pagaba $45 \%$ del valor de la leche y se les suministraban todos los instrumentos de trabajo. La empresa también poseía cuatro fábricas de queso, con una capacidad anual de 3000 toneladas, aunque a comienzos de la década de 1950 sólo producía la mitad de esa cifra.

${ }^{58}$ DSCDN, 1952, vol. 1, p. 364.

${ }^{59} \mathrm{AGN}, \mathrm{CAB}, \mathrm{ACA}$, Sesión 7, 10 de junio de 1953 , vol. 24, p. 195. 
Adicionalmente, Santa Rosa administraba campos de terceros ( 75486 hectáreas), las que arrendaba al tanto por ciento, y por las cuales cobraba a sus propietarios $5 \%$ de las entradas brutas. Otras empresas agrarias eran Invernadas San Sebastián y Colonias y Estancias El Rodeo. Ambas firmas eran propietarias de tierras, que arrendaban a otras empresas Bemberg o bien a chacareros y a colonos. La administración de estas empresas llevó a la $C A B$ a decidir su fusión con Estancias Santa Rosa. ${ }^{60}$

$\mathrm{L} a$ administración estatal de Estancias Santa Rosa se caracterizó por un mayor dinamismo en relación con otros establecimientos agrarios. En enero de 1954, la organización de la empresa sufrió cambios importantes mediante la creación de cuatro departamentos destinados a la administración, la producción industrial, las ventas y la administración de las estancias y colonias puestas bajo su órbita. ${ }^{61}$ Ese año, la gerencia ordenó la creación de quince nuevos tambos para incrementar la producción de leche, la adquisición de 2500 cabezas de ganado, la compra de maquinaria agrícola con el objetivo de reemplazar los servicios prestados por contratistas, y la intensificación del cultivo de tierras. El resultado fue que la producción de leche se elevó $70 \%$, en tanto que la superficie cultivada se incrementó de 10200 hectáreas a $21057 .{ }^{62}$

En cambio, en otras empresas, la administración estatal se mostraba incapaz para detener su deterioro productivo. Un caso

${ }^{60}$ AGN, CAB, ACA, Sesión 42, 10 de febrero de 1954, vol. 27, p. 183.

${ }^{61}$ AGN, CAB, ACA, Sesión 41, 3 de febrero de 1954, vol. 27, p. 154.

${ }^{62} \mathrm{AGN}, \mathrm{CAB}, \mathrm{ACA}$, Sesión 125, 14 de septiembre de 1955 , vol. 35 , p. $120-127$. típico era el de la Cía. Argentina Industrial Olivícola, fundada en 1939, que no había alcanzado la maduración de sus inversiones en olivares y sólo la mitad de la plantación estaba en explotación hacia 1950. La falta de inversiones y el progresivo abandono en que entró la explotación a partir de 1953 , acentuarían las pérdidas económicas hasta hacer inviable a la empresa.

El deterioro productivo pudo observarse también en el caso de SAFAC, firma que tenía actividades diversificadas en las finanzas, los negocios inmobiliarios, la producción de malta y de yerba mate. ${ }^{63}$ Para esta última tarea se habían adquirido 25000 hectáreas en Misiones donde se cultivaba yerba mate, logrando abastecer, para 1948, el $10 \%$ del consumo nacional. Ese año, el inicio de la liquidación de Puerto Bemberg marcó el comienzo de un notable deterioro de la explotación y de la rentabilidad. Luego de la nacionalización se ensayó reestructurar la empresa sobre la base de la producción yerbatera, ya que las acciones y las propiedades urbanas administradas por SAFAC fueron transferidas a manos de CIFA y la Maltería Rosario al grupo cervecero. Con este objetivo, se decidió la readquisición de un molino y se lanzó una enérgica campaña de propaganda, pero a pesar de ello el quebranto de la empresa se acentuó. ${ }^{64}$

La administración cedió muy pronto ante la postura privatizadora. En septiembre de 1954, los trabajadores yerbateros formaron una cooperativa y propusieron la compra del establecimiento. En abril del

${ }^{63}$ El patrimonio neto ascendía a 175000000 de pesos, correspondiendo $70 \%$ al rubro administración de propiedades e inversiones financieras; $21 \%$ a la Maltería Rosario y $9 \%$ a la explotación yerbatera.

${ }^{64} \mathrm{AGN}, \mathrm{CAB}, \mathrm{ACA}$, Sesión 125, 14 de septiembre de 1955 , vol. 35 , pp. 132-133. 
año siguiente se acordó la venta de 7000 hectáreas por 8500000 de pesos a la $\mathrm{CoO}$ perativa 17 de Octubre. ${ }^{65}$ En ese momento, el gobierno proyectaba un plan de colonización y liquidación de las empresas agrarias, así como la venta de los inmuebles urbanos y rurales a sus inquilinos y colonos, respectivamente. Para 1957, se habían vendido cerca de 52300 hectáreas del patrimonio total del grupo.

\section{EL LENTO RETORNO DE LOS BEMBERG, 1955-1959}

En septiembre de 1955, el derrocamiento de Perón abrió una nueva etapa. A pesar de ello, la recuperación de los bienes por parte de la familia Bemberg y el reconocimiento de los presuntos derechos de los accionistas se producirían cuatro años más tarde. Con respecto a estos últimos reclamos, el gobierno peronista había tenido inicialmente una respuesta muy dura, recomendando a los accionistas el empleo de la vía judicial. ${ }^{66}$

Contra lo que esperaba la familia Bemberg, el gobierno de la "revolución libertadora" titubeó ante su pedido de devolución de los bienes. ${ }^{67}$ En mayo de 1956, el ministro de Hacienda declaró que los propietarios y accionistas debían seguir la

65 AGN, CAB, ACA, Sesión 104, 27 de abril de 1955, vol. 33, pp. 140-141. En 1956 el convenio fue anulado.

${ }^{66}$ En 1953, la Association Nationale des Porteurs Français des Valeurs Mobilières, en representación de los accionistas de Cervecería Palermo y SAFAC, rechazó por ilegal la nacionalización de las empresas. Como respuesta, se ordenó vender acciones en poder de $\mathrm{Pa}$ lermo. $A G N, C A B, A C A$, Sesión 29, 4 de noviembre de 1953 , vol. 26 , p. 142.

${ }^{67}$ Saravia, Esclarecimiento, 1956. vía judicial. ${ }^{68}$ Esta cautela estaba vinculada a la importancia económica de las empresas, pero también a la sospecha de que la nacionalización de las empresas no había sido un acto infundado. El camino del reconocimiento judicial de los derechos era también el preferido por el gobierno francés, cuya presión se había acentuado como consecuencia del inicio de las negociaciones tendentes a restablecer el comercio multilateral con Europa occidental. ${ }^{69}$

Mientras tanto, la administración de las empresas sufría los problemas derivados de los continuos cambios en los elencos oficiales. Las reuniones de la $\mathrm{CAB}$, que se habían realizado una vez por semana durante los años de Perón, comenzaron a hacerse una sola vez por mes, con lo que la administración estatal quedó de hecho a cargo del gerente general, El gobierno militar tampoco intentó adecuar a la CAB al decreto $5883 / 55$ que reglamentaba la ley de empresas públicas. La medida ordenaba la elevación anticipada de un plan de acción anual donde debían detallarse los objetivos propuestos por las empresas y las fuentes de recursos que planeaban utilizar. El incumplimiento de esta ley mostraba que las empresas no tenían objetivos a cumplir. A ello se sumó el criterio de la CAB de no innovar en la administración de las empresas. Más alarmante aún era que la alta rotación de los gerentes de las empresas y la falta de capacidades administrativas mínimas ponían en serio riesgo la situación patrimonial de las firmas. ${ }^{70}$

${ }^{68}$ AGN, CAB, ACA, Sesión 133, 3 de mayo de 1956, vol. 35, p. 198.

${ }^{69}$ García Heras, "Argentina", 1996, pp. 1277 1308.

70 Tribunal de Cuentas de la Nación, Memoria del 1er. Ejercicio. Año 1956, Buenos Aires, 1957, p. 308. 
Por fin, a partir de mayo de 1957, se conocieron las primeras sentencias de la justicia que, con pocas excepciones, beneficiaron a la familia Bemberg y otros accionistas. En total, 18 fallos anularon la inclusión de varias empresas en la ley $14.122 \mathrm{o}$ bien declararon inconstitucional esa norma. ${ }^{71}$

En mayo de 1958, la asunción del presidente Arturo Frondizi marcó un cambio importante sin haber agotado las instancias judiciales: el nuevo gobierno optó por el camino del acuerdo extrajudicial con los Bemberg. Esta estrategia estaba orientada a resolver los problemas generados por las nacionalizaciones peronistas y tenía como objetivo alentar el ingreso masivo de capitales extranjeros, que era un aspecto clave de la política de Frondizi.

Las negociaciones culminaron en enero de 1959 con la firma de varios convenios entre el Estado nacional y la Brasserie Argentine Quilmes, la familia Bemberg y las empresas nacionalizadas. La parte más importante del acuerdo establecía que los "dueños legítimos" de las empresas las recibirían en el estado en que estuvieran, devolviendo al Tesoro los montos depositados por el gobierno en el momento de su adjudicación, en tanto que se extinguía toda responsabilidad legal del Estado federal por el pago de costas, daños y perjuicios. Por su parte, el Estado nacional acataba la declaración de inconstitucional de la ley que había expropiado los bienes inmuebles de la familia Bemberg. ${ }^{72}$

El acuerdo significaba concesiones importantes del gobierno. El procurador del

${ }^{71}$ El listado completo de los fallos figura en $L a$ Prensa, 27 de enero de 1959, p. 5.

${ }^{72}$ Decreto 547 del 16 de enero de 1959, en $A L A$, 1959, pp. 2-3.
Tesoro se mostró contrario a esa posición, ya que entendía que la devolución de las empresas sólo podía ser dispuesta por una ley del Congreso. Consideraba que su único aspecto positivo era la aceptación de los bienes en el estado en que se encontraban, aunque advertía que ello no era decisivo pues estaban "prácticamente igual". Por último, advertía que con el convenio "se reconstruye el grupo Bemberg en todo el país y se da patente al nuevo seguro monopolio cervecero". ${ }^{73}$

Para el grupo Bemberg, el convenio ponía fin al pleito en un momento en que la asunción de la nueva Corte Suprema de Justicia abría una incógnita sobre el resultado final de los litigios judiciales. La devolución de las empresas demandaría una reorganización amplia del grupo, que volvería muy pronto a controlar a la industria cervecera.

\section{CONSIDERACIONES FINALES}

El proceso Bemberg fue el ataque más importante llevado en contra de un conglomerado en Argentina durante la primera mitad del siglo Xx. Apoyado en una demanda impositiva, vinculada a la forma de organización del holding, Perón desplegó las fuerzas del Estado contra el grupo empresario. La nacionalización de las empresas constituyó también una respuesta simbólica a la década de 1930, que era recordada como un tiempo de humillaciones y frustraciones para el movimiento obrero.

${ }^{73}$ Ricardo Columbres "Memorando básico sobre el caso Bemberg para el presidente Frondizi", 9 de diciembre de 1958. Biblioteca Nacional, Archivo Frondizi. 
Pero el éxito simbólico de esa medida era sólo una parte de la cuestión. La nacionalización no resolvió el problema de qué hacer con un nutrido grupo de empresas que representaban cuantiosos capitales y aproximadamente 10000 puestos de trabajo. El gobierno de Perón creó una nueva empresa pública, que se reconocía como una entidad provisional hasta tanto se lograse la privatización de las firmas. El fracaso estatal a la hora de revertir los problemas de las empresas y el surgimiento de demandas obreras a favor de la organización de sociedades con participación de los trabajadores, permitió al peronismo llevar adelante algunos de sus proyectos más ambiciosos con el traslado de la industria cervecera a una cooperativa sindical y la cesión del establecimiento yerbatero Puerto Bemberg a una cooperativa obrera. Estos caminos quedaron truncos cuando el gobierno militar anuló estos contratos. Entonces, la decisión oficial de "no innovar" en el manejo de las empresas y la inestabilidad de sus cuadros gerenciales consolidaron el deterioro de las firmas.

La posición oficial de no devolver las empresas a menos que mediara sentencia judicial ponía en evidencia que aun para los antiperonistas, la imagen que se tenía del grupo Bemberg estaba cubierta de sospechas. Sólo a partir de 1958, Frondizi aceleraría la devolución de las empresas por medio de un acuerdo directo y con el objetivo puesto en atraer al capital extranjero.

Si bien el caso Bemberg fue excepcional, ilustra la compleja dinámica que asumieron las relaciones entre el Estado, los grupos empresariales y el capital extranjero a partir de 1943, momento en que el nacionalismo económico adquirió gran auge. El fracaso estatal en imponer normas que apaciguaran las fallas de mercado duran- te el periodo de entreguerras, fue seguido de un reforzamiento del poder estatal durante el peronismo. Al mismo tiempo, el caso Bemberg revela los límites de las capacidades estatales en relación con la creación y administración de empresas públicas. Ambas temáticas requieren mayor exploración pero, sin dudas, constituyen problemáticas centrales a la hora de explicar el derrotero argentino.

\section{Fuentes CONSUltadas}

\section{Arcbivos}

AGN Archivo General de la Nación.

BN Biblioteca Nacional.

\section{Hemerografía}

Anales de Legislación Argentina, 1946-1959.

Boletín de la Cámara de Comercio Argentina Alemana, 1953-1959.

Camoatí. Revista de Economía y Estadística, 19441946.

Diario de Sesiones de la Cámara de Diputados, 1919-1955.

Diario de Sesiones de la Cámara de Senadores, 19461955.

La Industria Cervecera, 1931-1951.

La Prensa, 1959.

Temas Económicos e Industriales, 1944.

Tribunal de Cuentas de la Nación, Memoria anual, 1956-1960.

\section{Bibliografía}

-Armour Research Foundation, Technological and economic sumvey of argentine industries with industrial research recommendations, Corporación para el Fomento del Intercambio, Chicago, 1943. 
-Belini, Claudio "DINIE y los límites de la política industrial peronista, 1947-1955" en Desarrollo Económico, vol. 41, núm. 161, abril-junio de 2001, pp. 97-119, Buenos Aires.

, "La industria durante el primer peronismo. Un análisis de las políticas públicas y de su impacto", tesis de doctorado, Universidad de Buenos Aires, 2004.

-Bertino, Magdalena "Integración y estructura del capital en la industria textil uruguaya, 1930-1960", tesis de maestría, Universidad de la República, Montevideo, 2004.

- Cámara de Comercio de los Estados Unidos, La Argentina y las firmas norteamericanas, Santiago Rueda Editor, Buenos Aires, 1958.

-El Caso Bemberg. Alegato de bien probado del fisco nacional y sentencia del juez en lo Civil Dr. Ismael Segovia, s.e., Buenos Aires, 1950.

-Francioni, Manuel y Mauricio Greffier, Los boldings. Problemas económicos y cuestiones jurídicas que plantean, El Ateneo, Buenos Aires, 1944.

-García Heras, Raúl "La Argentina y el Club de París: comercio y pagos multilaterales con la Europa occidental, 1955-1958", El Trimestre Económico, octubre y diciembre de 1996, México, pp. 1277-1308.

-Girbal-Blacha, Noemí, Mitos, paradojas y realidades, Universidad Nacional de Quilmes, Bernal, 2003.

-López, Sergio, "Integración y especialización como estrategias empresariales. El caso de la Cervecería Quilmes, 1890-1990", tesis de maestría, Universidad de San Andrés, 2001.

-Lewis, Paul, La crisis del capitalismo argentino, FCE, Buenos Aires, 1993.

-Marichal, Carlos "La gran burguesía comercial y financiera de Buenos Aires. Anatomía de cinco grupos, 1860-1914", mimeo., Buenos Aires, 1998.
-Musacchio, Paulino, Impuesto a la transmisión gratuita de bienes. Ocultación dolosa. Escrito presentado en los autos sucesorios de Otto S. Bemberg por el delegado interventor del Consejo Nacional de Educación, Talleres Gráficos del Consejo Nacional de Educación, Buenos Aires, 1947.

-OECEI, Argentina económica y financiera, s. e., Buenos Aires, 1966.

-Pineda, Yovanna, "Sources of finance and reputation. Merchant finance groups in argentine industrialization, 1890-1930", Latin American Research Review, vol. 41, núm. 2, 2006, pp. 3-30.

-Regalsky, Andrés, Mercados, inversores y elites. Las inversiones francesas en la Argentina, 1880 1914, Eduntref, Buenos Aires, 2002.

-Rocchi, Fernando, "Building a nation, building a market. Industrial growth and the domestic economy in the turn of the century Argentina", tesis de doctorado, University of California, Santa Bárbara, 1997.

-Rougier, Marcelo, La política crediticia del Banco Industrial durante el primer peronismo, Facultad de Ciencias Económicas/CEFED, Buenos Aires, 2001.

-Saravia, José Manuel, Hacia el esclarecimiento del caso Bemberg, Estudio Cárcano y Segovia, Buenos Aires, 1956.

-Smith, Peter, Carne y politica en la Argentina, Paidós, Buenos Aires, 1968.

-Schvarzer, Jorge, La industria que supimos conseguir, Planeta, Buenos Aires, 1996.

-Torres, José Luis, Los Perduellis. Los enemigos internos de la patria, Talleres Gráficos Padilla y Contreras, Buenos Aires, 1943.

-Vicepresidencia de la Nación, Documentación, autores y cómplices de las irregularidades cometidas durante la Segunda Tiranía, Vicepresidencia de la Nación, Buenos Aires, 1958, t. III. 